\title{
The impact of distraction minimization on endoscopic mentoring and performance
}

\section{(ㄷ)(1)}

Authors

Sean C. Rice ${ }^{1}$, James C. Slaughter ${ }^{2}$, Walter Smalley ${ }^{1,3}$, Keith L. Obstein ${ }^{1,4}$

Institutions

1 Division of Gastroenterology, Vanderbilt University, Nashville, Tennessee, United States

2 Department of Biostatistics, Vanderbilt University, Nashville, Tennessee, United States

3 Division of Gastroenterology, Nashville Veterans Affairs Hospital, Nashville, Tennessee, United States

4 Department of Mechanical Engineering, Vanderbilt University, Nashville, Tennessee, United States

submitted 6.7.2020

accepted after revision $\quad 6.8 .2020$

Bibliography

Endoscopy International Open 2020; 08: E1804-E1810

DOI 10.1055/a-1265-6731

ISSN 2364-3722

(c) 2020. The Author(s).

This is an open access article published by Thieme under the terms of the Creative Commons Attribution-NonDerivative-NonCommercial License, permitting copying and reproduction so long as the original work is given appropriate credit. Contents may not be used for commecial purposes, or adapted, remixed, transformed or built upon. (https://creativecommons.org/licenses/by-nc-nd/4.0/)

Corresponding author

Keith L. Obstein, Vanderbilt University Medical Center, 1301 Medical Center Drive, 1660 TVC, Nashville, TN 37232-5280, United States

Fax: +1-615-343-8174

keith.obstein@vumc.org

\section{ABSTRACT}

Background and study aims Endoscopic mentoring requires active attention by the preceptor. Unfortunately, sources of distraction are abundant during endoscopic pre- cepting. The impact of distraction minimization on endoscopic mentoring and performance is unknown.

Methods Fellow and attending preceptors were paired and randomized in a prospective crossover design to perform esophagogastroduodenoscopy (EGD) and/or colonoscopy in either a "distraction minimization" (DM) or a "standard" (S) room. Cell phones, pagers, music, and computers were not permitted in DM rooms. $S$ rooms operated under typical conditions. Fellows and attendings then completed a survey. The primary outcome was fellow satisfaction with mentoring experience (visual analogue scale: $0=\min , 100=$ max). Additional fellow outcomes included satisfaction of attending attentiveness, identifying landmarks, communication, and distractedness; attending outcomes included satisfaction with mentoring, attentiveness, communication, and distractedness. Endoscopic performance measures included completion of EGD, cecal intubation rate, cecal intubation time, withdrawal time, total procedure time, attending assistance, and polyp detection rate. A paired $t$ test was used to compare mean differences (MD) between rooms; significance set at $P<0.05$.

Results Eight fellows and seven attendings completed 164 procedures. Despite a trend toward less distraction between rooms $(\mathrm{DM}=12.5$ v. $S=18.3, \mathrm{MD}=4.1, P=0.17$ ), there was no difference in fellow satisfaction with training/ mentoring ( $D M=93, S=93, M D=-0.04, P=0.97)$, attentiveness $(D M=95, S=92, M D=0.86, P=0.77)$, identifying pathology/landmarks ( $D M=94, S=94, M D=-1.72, P=0.56)$, or communication (DM=95, $S=95, M D=1.0, P=0.37$ ). Similarly, there was no difference between rooms for any attending outcome measures or performance metrics.

Conclusions DM did not improve perceived quality of endoscopic mentoring or performance for fellows or attendings; however, reduced distraction may improve attending engagement/availability.

\section{Introduction}

The education and training of gastroenterology fellows, particularly during endoscopy, can be challenging for both the trainee and preceptor. Prior studies that define acquisition of endoscopic competency and evaluation of various instructional methods such as simulator education are well-established [1$4]$. Despite these publications, no study focuses directly on evaluation of the endoscopic mentoring relationship. The establishment of an effective teaching/mentoring relationship can significantly impact overall endoscopic training and subsequent performance. Effective mentoring ideally takes place in 
an endoscopy suite with full attention of the preceptor and minimal distraction. A critical part of mentoring involves uninterrupted communication and focus; however, multiple sources of distraction (computers, cell phones, tablets, pagers etc.) are abundant, and can negatively impact the endoscopic mentoring experience. Moreover, prior studies have shown that communication failures within healthcare institutions can increase the likelihood of adverse events [5]. Distractions in procedural areas can create misunderstandings and result in otherwise preventable errors [6].

There has been evidence suggesting that a "sterile cockpit approach" used in aviation can help minimize distractions. The Sterile Cockpit Rule is a Federal Aviation Administration (FAA) regulation requiring aircraft pilots to refrain from non-essential activities in the cockpit during critical phases of flight [7]. Prior studies have noted that implementation of the sterile cockpit methodology led to a significant reduction in observed interruptions and improved awareness of distractions in the gastroenterology procedural area. Furthermore, a recent study identified distractedness as a target to address given the potential relationship with adenoma detection rate (ADR) $[8,9]$.

While no prior studies have directly evaluated the impact of distraction on endoscopic training in a gastroenterology unit, some have shown detrimental effects on teamwork, workload, and stress on members of operating room teams [10]. Conversely, one prior study used a novel tablet application to focus mentor attention on trainee polyp detection, which resulted in reduced stress, quicker polyp identification, and improved educational satisfaction [11].

To our knowledge, the use of distraction elimination/minimization has not been studied in the setting of endoscopic training. Our study was designed to evaluate the impact of distraction elimination/minimization on endoscopic mentoring and performance in a clinical setting. We hypothesized that distraction minimization would improve perceived endoscopic mentoring for fellows and attendings and improve endoscopic performance metrics.

\section{Methods}

\section{Overview}

A prospective, randomized, crossover study was conducted of fellow and attending physicians performing esophagogastroduodenoscopy (EGD) and colonoscopy (CLS) at the Tennessee Valley Healthcare System (TVHS) Nashville Veterans Affairs Hospital in Nashville, TN from January 2019 through May 2019. The protocol was IRB approved (TVHS IRB [protocol number 1298089-1 under Title 38 CFR 16.101(b) Category 2]).

\section{Participants, interventions and room design}

Eight fellow physicians and seven attending physicians were enrolled to participate in the study. Each was assigned a unique letter identification code to ensure anonymity in the data acquisition process. Basic fellow/attending demographics without personal identifying information was recorded. Participation in the study was voluntary and all participants retained the right to withdraw from the study at any time. The study

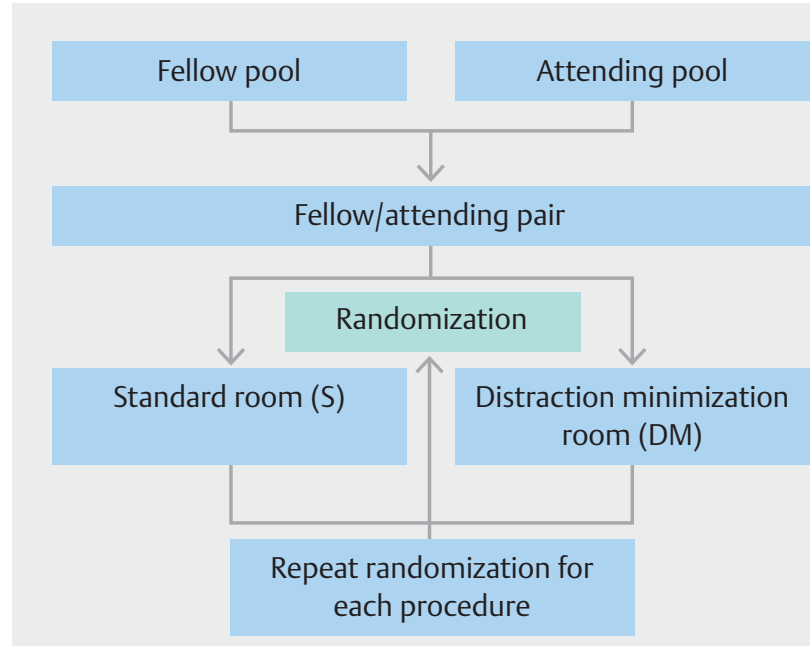

- Fig. 1 Daily room assignment protocol.

was IRB approved for implied consent and a descriptive summary of the study was presented prior to study commencement, but otherwise study personnel did not interact with participants. No patient information was collected for the study. The authors of the paper were not permitted to participate in endoscopy. Exclusion criteria for cases included surgically altered anatomy (i.e prior history of ileo-cecectomy or hemicolectomy).

For each procedure, one fellow worked with one attending who was present for the entire duration of the endoscopy. Each fellow was assigned to different attendings throughout the study period. Prior to procedure initiation, each fellow/attending pair was randomized to either "distraction minimization" (DM) or "standard room" (S) via a sealed envelope prior to room entry ( $\mathbf{F i g . 1}$ ). Randomization sequence was generated via random number generator. In the "distraction minimization" rooms, fellow/attending use of any electronic device was prohibited. Secured, opaque, vibration-proof boxes were provided in each room to place phones, pagers, tablets, or smart watches. Physician computer monitors were turned off during the entire duration of the procedure. Non-essential staff were not permitted in the procedure rooms, and no personnel were permitted to enter or leave the endoscopy room once a procedure started unless necessitated by the case (i.e. additional equipment or personnel needed). A sign was posted outside of each procedure room alerting the staff of entry restrictions. No music was permitted in the rooms. In "standard rooms," there were no restrictions and the procedures took place under typical daily conditions.

After completion of each procedure, the fellow and attending independently completed separate forms and returned them to a secure location. The forms were collected by research staff who were not directly involved with the procedure or in direct contact with the study participants. Data was subsequently entered into a secure data repository (Vanderbilt University Medical Center Redcap database (REDCap; UL1 TR000445 from NCATS/NIH) [12]. 


\section{Objectives/outcomes}

The main outcome measure was fellow "Satisfaction with Training and Mentoring" as measured by a previously validated 100 point visual analogue scale (VAS) [13]. Additional outcomes measured included "Ease of Communication," "Ease of Identifying pathology/Anatomic Landmarks," "Satisfaction with Attentiveness of Attending Physician," and "Level of Distractedness." Similarly, attending physicians completed a similar post procedure survey instrument that measured "Overall Satisfaction with Mentoring Experience," "Ease of Communication," "Level of Distractedness," and "Level of Attentiveness."

Endoscopic performance metrics were collected for each case and included successful examination of the esophagus, stomach, and duodenum (including retroflexion in the stomach) for upper endoscopies and cecal intubation rate, cecal intubation time, withdrawal time, total procedure time, need for hands on attending assistance, and polyp detection rate (PDR) for colonoscopies. Cecal intubation time was defined as the difference in time between time of anal insertion of colonoscope and first visualization of the appendiceal orifice (AO). Withdrawal time was defined as the difference between time of visualization of AO and procedure end time. Total procedure time was defined as the difference between time of colonoscope insertion and procedure end time. Polyp detection rate was defined as the proportion of colonoscopies in which at least one polyp is detected for each endoscopist.

\section{Statistical analysis}

We planned a study with 20 pairs of subjects. We estimated that the difference in the response of matched pairs is normally distributed with a standard deviation of 12 (this assumes a standard deviation of 20 with a correlation among repeated measurements on the same fellow of 0.7 ). Using this framework, we are able to detect a true difference in the mean response of matched pairs of -9.179 or 9.179 with probability (power) 0.9 and detect a true difference in the mean response of matched pairs of -7.926 or 7.926 with probability (power) 0.8 . The Type I error probability associated with this test of the null hypothesis is 0.05 . Each outcome considered was analyzed and processed in a similar manner. The outcome was averaged over the type of room (DM or S) for each fellow and attending to create an average score in both types of room for each person. Paired t-tests were used to compare a subject's average score in the DM room to the same subject's average score in the $\mathrm{S}$ room. Results are presented as mean differences over all subjects (DM minus S) with corresponding $95 \% \mathrm{Cl}$ to determine if the type of room was associated with a change in outcome allowing for each subject to serve as his/her own control with equal weight in the analysis.

\section{Results}

\section{Fellow and attending characteristics}

A total of eight fellow physicians ( 5 males, 3 females) and seven attending physicians ( 5 males, 2 females) participated in the study. Specific details regarding each endoscopists demographics and prior experience is included in $>$ Table 1.

\section{Satisfaction with mentoring experience and endoscopic performance metrics}

A total of 164 procedures were performed by the fellow/attending pairs $(E G D s=66$, Colonoscopies $=98)$. Despite a trend toward less overall distraction between rooms, there was no statistically significant difference in overall fellow satisfaction with training/mentoring, attending attentiveness, identifying pathology/anatomic landmarks or ease of communication ( $\triangleright$ Table 2). Notably, for the "level of distractedness" VAS, a score of " 0 " meant least distracted, and a score of " 100 " meant most distracted. This reversal of scale was clearly noted in the post procedural survey. Similarly, there was no significant difference for any outcome measure for attendings ( $\triangleright$ Table 2 ).

Performance metrics between the two groups were also similar and no statistically significant difference was noted between rooms for cecal intubation time $(D M=6 \mathrm{~min} 42 \mathrm{~s}, \mathrm{~S}=8$ $\min 42 \mathrm{~s}, \mathrm{MD}=-1.58, \mathrm{p}=0.44,[95 \% \mathrm{Cl},-6.1-3.0]$ ), withdrawal time $(D M=19 \mathrm{~min}, S=20 \mathrm{~min}, M D=1.25, p=0.63,[95 \% \mathrm{Cl}$, $-4.6-7.1])$, total procedure time $(D M=27 \mathrm{~min}, S=29 \mathrm{~min}$, $\mathrm{MD}=-0.23, \mathrm{p}=0.92,[95 \% \mathrm{Cl},-5.3-4.9])$, or $\mathrm{PDR}(\mathrm{DM}=73 \%$, $\mathrm{S}=74 \%, \mathrm{MD}=0.02, P=0.85,[95 \% \mathrm{Cl},-0.25-0.30]$ ) ( Table 3 ). There was no difference in successful completion of EGD or cecal intubation as both arms in each category were $100 \%$ among all fellows. In addition, there was no statistically significant difference regarding need for attending assistance ( $\triangleright$ Table 4 ).

\section{Discussion}

Effective mentoring of trainees in endoscopy requires active attention by the preceptor in an educational environment. As multiple sources of frequent distraction are common in endoscopy suites during training, we set to evaluate the impact of distraction minimization on endoscopic mentoring and performance. Studies regarding the impact of distraction minimization on training have been nearly vacant from the literature. Most studies involving distraction minimization reflect on patient safety outcomes, which have shown promise; however, none of the studies show that distraction minimization had impact on proficiency metrics (i.e complication rates, length of hospital stay, length of procedure). Our study was unique in that it: (1) Used a prospective cross over design to compare fellows to themselves in two different mentoring environments; (2) studied the effect of distraction minimization on trainee satisfaction with mentoring; and (3) studied the impact of distraction minimization on well-defined endoscopic proficiency metrics.

Contrary to our hypothesis, we found that distraction minimization did not improve fellow or attending mentoring outcomes despite trends towards less distraction. Notably, however, while there was no difference in mentoring or performance outcomes between DMand S rooms, both arms had high overall mentoring scores (all scores were >90) and performance outcomes (relatively quick cecal intubation times, low to- 
- Table 1 Endoscopist demographics.

\begin{tabular}{|c|c|c|c|c|c|}
\hline Fellow & Gender & Year in fellowship training & Total prior EGDs & \multicolumn{2}{|c|}{ Total prior colonoscopies } \\
\hline G & Female & 1 & $50-99$ & \multicolumn{2}{|l|}{$21-49$} \\
\hline $\mathrm{Q}$ & Female & 1 & $26-49$ & \multicolumn{2}{|l|}{$21-49$} \\
\hline $\mathrm{O}$ & Female & 1 & $50-99$ & \multicolumn{2}{|l|}{$50-99$} \\
\hline $\mathrm{F}$ & Male & 2 & $>200$ & \multicolumn{2}{|l|}{$>200$} \\
\hline$P$ & Male & 2 & $>200$ & \multicolumn{2}{|l|}{$>200$} \\
\hline $\mathrm{T}$ & Male & 2 & $>200$ & \multicolumn{2}{|l|}{$>200$} \\
\hline s & Male & 2 & $>200$ & \multicolumn{2}{|l|}{$>200$} \\
\hline$U$ & Male & 3 & $>200$ & \multicolumn{2}{|l|}{$>200$} \\
\hline Attending & Gender & Total years in practice & Total years mentoring fellows & Total EGDs & Total colonoscopies \\
\hline A & Male & 20 & 13 & $>1000$ & $>1000$ \\
\hline B & Male & 20 & 20 & $>1000$ & $>1000$ \\
\hline$C$ & Female & 3.5 & 3.5 & $>1000$ & $>1000$ \\
\hline $\mathrm{E}$ & Female & 11 & 11 & $>1000$ & $>1000$ \\
\hline $\mathrm{H}$ & Male & 9 & 9 & $>1000$ & $>1000$ \\
\hline J & Male & 30 & 27 & $>1000$ & $>1000$ \\
\hline K & Male & 10 & 10 & $>1000$ & $>1000$ \\
\hline
\end{tabular}

- Table 2 Satisfaction of fellows and attendings with mentoring experience.

\begin{tabular}{|c|c|c|c|c|c|c|}
\hline Group & Visual analogue scale & $\begin{array}{l}\text { Distraction minimi- } \\
\text { zation room }(0= \\
\min , 100=\max )^{1}\end{array}$ & $\begin{array}{l}\text { Standard room } \\
(0=\min , 100= \\
\max )^{1}\end{array}$ & $\begin{array}{l}\text { Mean differ- } \\
\text { ence (MD) be- } \\
\text { tween rooms }\end{array}$ & $P$ value & $\begin{array}{l}95 \% \text { confidence } \\
\text { interval }\end{array}$ \\
\hline \multirow[t]{5}{*}{$\begin{array}{l}\text { Fellows } \\
(\mathrm{n}=8)\end{array}$} & $\begin{array}{l}\text { Overall satisfaction with train- } \\
\text { ing/ mentoring }\end{array}$ & 93 & 93 & -0.04 & 0.97 & $-2.46-2.37$ \\
\hline & Ease of Communication & 95 & 95 & 1.00 & 0.37 & $-1.5-3.5$ \\
\hline & $\begin{array}{l}\text { Ease of Identifying pathology/ } \\
\text { anatomic landmarks }\end{array}$ & 94 & 94 & -1.73 & 0.56 & $-8.5-5.0$ \\
\hline & Level of distractedness ${ }^{2}$ & 12.5 & 18.3 & -4.12 & 0.17 & $-10.5-2.2$ \\
\hline & $\begin{array}{l}\text { Satisfaction with attentiveness } \\
\text { of attending physicians }\end{array}$ & 95 & 92 & 0.86 & 0.77 & $-5.8-7.5$ \\
\hline \multirow[t]{4}{*}{$\begin{array}{l}\text { Attendings } \\
(\mathrm{n}=7)\end{array}$} & $\begin{array}{l}\text { Overall satisfaction with men- } \\
\text { toring experience }\end{array}$ & 94 & 91 & 1.38 & 0.61 & $--4.9-7.7$ \\
\hline & Ease of communication & 92 & 94 & 1.56 & 0.56 & $-4.6-7.7$ \\
\hline & Level of distractedness & 14.6 & 20.0 & -1.56 & 0.59 & $-8.3-5.22$ \\
\hline & Level of attentiveness & 92 & 88 & 0.47 & 0.61 & $-1.6-2.5$ \\
\hline \multicolumn{7}{|c|}{$\begin{array}{l}\text { "Scoring scale is from } 0 \text { to } 100 \text { where " } 0 \text { " is the minimum and " } 100 \text { " is the maximum. Fellow scores are the mean for all fellows; attending scores are the mean for all } \\
\text { attendings. } \\
2 \text { For level of distractedness, a score of "0" meant least distracted, and a score of " } 100 \text { " meant most distracted }\end{array}$} \\
\hline
\end{tabular}

tal procedure times, high cecal intubation rate, high EGD completion rate, and high PDR).

When examining individual trends for fellow distraction, six fellows noted reduced levels of distraction, while two (both sec- ond-year fellows) reported increased distraction while in DM rooms compared to S rooms ( $\triangleright$ Fig. 2 ). Given the presumed increased experience/competence relative to more junior fellows in the study, it is possible that increased mentor attention itself 
- Table 3 Performance metrics.

\begin{tabular}{|l|l|l|l|}
\hline Metric & $\begin{array}{l}\text { Distraction minimization room } \\
\left(\mathbf{n = 8} \mathbf{1}^{\mathbf{1}}\right.\end{array}$ & $\begin{array}{l}\text { Standard room } \\
(\mathbf{n = 8})^{\mathbf{1}}\end{array}$ & $\begin{array}{l}\text { Mean difference } \\
\text { (MD) }\end{array}$ \\
\hline EGD completion rate (\%) & 100 & 100 & 0.00 \\
\hline Cecal intubation rate (\%) & 100 & 100 & 0.00 \\
\hline Withdrawal time (minutes) & 19 & 20 & 1.25 \\
\hline Cecal intubation time (minutes:seconds) & $6: 42$ & $8: 42$ & -1.58 \\
\hline Total procedure time (minutes) & 27 & 29 & -0.23 \\
\hline Polyp detection rate (\%) & 73 & 74 & 0.02 \\
\hline $\begin{array}{l}\text { EGD, esophagogastroduodenoscopy. } \\
\text { (All scores are averaged over fellows. }\end{array}$ & & & 0.03 \\
\hline
\end{tabular}

- Table4 Need for attending assistance.

\begin{tabular}{|l|l|l|}
\hline $\begin{array}{l}\text { Percentage of the to- } \\
\text { tal endoscopic time } \\
\text { that required attend- } \\
\text { ing assistance (\%) }\end{array}$ & $\begin{array}{l}\text { DM cases requir- } \\
\text { ing attending } \\
\text { assistance } \mathbf{( n ;} \%)\end{array}$ & $\begin{array}{l}\text { S cases requir- } \\
\text { ing attending } \\
\text { assistance }(\mathbf{n} ; \%)\end{array}$ \\
\hline 0 & $7(87.5)$ & $6(75)$ \\
\hline 5 & $1(12.5)$ & 0 \\
\hline 10 & 0 & $1(12.5)$ \\
\hline 100 & 0 & $1(12.5)$ \\
\hline DM, distraction minimization; 5 , standard. \\
\hline
\end{tabular}

may have been more distracting. The results may suggest that more experienced fellows prefer a more autonomous environment when performing endoscopy and inherently become more distracted when another endoscopist is present. In addition, as attendings were not preoccupied by phones or computers, there may have been more conversation between fellows and preceptors causing more fellow distraction during endoscopy.

We found similar results for attendings. While pooled results showed less overall distraction, three of the seven attendings trended toward more distractedness in DMrooms compared to $S$ rooms - potentially as a result of them continuously thinking (consciously or unconsciously) about what was happening outside of the room (i.e. getting behind on emails; pages; EHR communications; etc.). Further studies to examine the impact of these distractions are underway.

While the sample size was limited due to the number of fellows available for the study, the results indicate that contrary to our hypothesis, distraction minimization may have the opposite effect of that intended in some individuals - i. e. causing more distraction by removing distractions. A matched study would be ideal; however, due to logistics (several scheduling conflicts of fellows and attendings, vacation time, medical leave, endoscopy lab closures etc.) this was prohibitive and therefore a cross-over design was implemented a priori. While there are no prior or baseline studies to serve as a reference for magni-

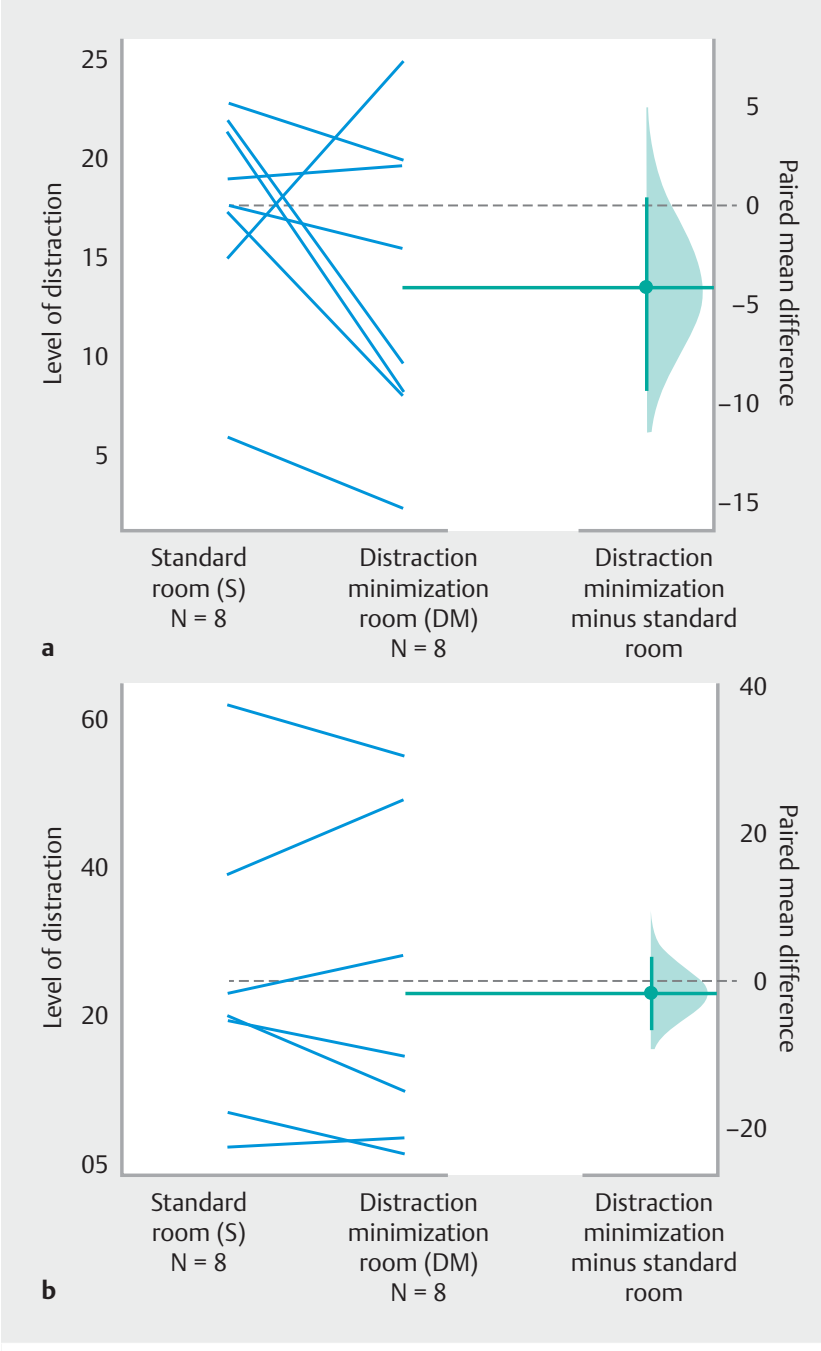

- Fig. 2 Individual distraction trends. a Change in fellow reported distraction. Each line represents a fellow. $\mathbf{b}$ Change in attending reported distraction. Each line represents an attending.

tude of improvement in distraction or satisfaction with training, we felt that the crossover nature of the study served as an adequate comparison of each fellow at baseline in an inherently more distracted environment. 
Our study took place in the second half of the academic year, so junior fellows were presumably more competent/experienced in endoscopy compared to a trial that started at the beginning of the academic year. Perhaps a study evaluating the same variables for a given trainee level stratified by time of academic year (i.e., first quarter vs fourth quarter) may lead to changes in significance. Notably, however, a subgroup analysis stratified by fellow training year showed no difference in any outcomes measured. Also, given the inherent differences and learning curves for EGD and colonoscopy - with colonoscopy generally considered to be more difficult to learn, we separately evaluated the outcomes for each fellow for EGD and colonoscopy, and no differences were noted.

We considered a mixed-method approach to include a post study survey; however, there was overall concern for compliance with an additional survey required to obtain this information. We did conduct informal debriefings with fellows and attending physicians after the study was concluded. Overall, fellows felt that there were many times where they felt paradoxically more distracted when the attendings were paying more attention and giving more advice (welcomed or unwelcomed) during cases. While attendings were not enthusiastic about surrendering access to their technology, they did feel more engaged overall in the teaching process.

While the use of several mentors in this study may function as a confounder given the subjective nature of outcomes, we felt that attending input about the educational experience was very important and therefore included a variety of mentors in the analysis to eliminate the chance that the results would be specific only to one mentor as different attendings provide different levels of feedback/engagement/teaching.

While our study design successfully eliminated distractions pertaining to the attending physicians and fellows, other distractions including technologists, nurses, and anesthesia staff still existed. As adequate training and mentoring is mostly focused on the interactions and distractedness of the fellow and attendings, we felt that distraction of others in the room would have minimal influence on the results. Finally, given the nature of the distraction minimization rooms and direct interaction with pairs of our study, our study was not able to be blinded. Therefore, it is possible that attendings were unconsciously/ consciously more engaged in mentoring during procedures regardless of which arm they were assigned (DM or S) - i. e. the Hawthorne effect.

Given the similarity in both mentoring and performance outcomes between DMand S rooms, the results of this study suggest that simply having an attending provider physically present during the entire duration of the procedure affects perceived mentoring and performance - as attending providers were physically present and readily available to help with questions and assist with procedures if needed in both study arms. While some fellowship programs require attendings to be present in the endoscopy suite for the entire duration of the procedure, others require that an attending physician be "immediately available" to assist fellows during endoscopy. As distraction minimization may improve engagement/availability, a multicenter trial comparing the two arms in this study with a third arm of "attending availability" would be helpful to delineate if further differences exist.

\section{Conclusion}

In summary, distraction minimization does not improve perceived quality of endoscopic mentoring for fellows or attendings or fellow performance when compared to standard instruction; but may improve attending engagement/availability. Our study suggests that simply having an attending provider in the endoscopy room may enhance the endoscopic educational experience when compared to having attendings immediately available. Studies evaluating distraction minimization and attending engagement/availability are underway.

\section{Acknowledgements}

The authors thank Vanderbilt University Medical Center and The Nashville Veterans Affairs Medical Center. Internal funding was by the Vanderbilt University Division of Gastroenterology.

\section{Competing interests}

The authors declare that they have no conflict of interest.

\section{References}

[1] Cass OW. Training to competence in gastrointestinal endoscopy: a plea for continuous measuring of objective end points. Endoscopy 1999; 31: 751-754

[2] Sedlack RE. Training to competency in colonoscopy: assessing and defining competency standards. Gastrointest Endosc 2011; 74: 355366.e351-352

[3] Ende A, Zopf Y, Konturek P et al. Strategies for training in diagnostic upper endoscopy: a prospective, randomized trial. Gastrointestinal endoscopy 2012; 75: 254-260

[4] Faulx AL, Soyka C. Simulator training in colonoscopy: when less is better. Gastrointest Endosc 2015; 81: 974-975

[5] Berenholtz SM, Schumacher K, Hayanga AJ et al. Implementing standardized operating room briefings and debriefings at a large regional medical center. Joint Commission J Quality Patient Safety 2009; 35: 391-397

[6] Hay JM, Barnette W, Shaw SE. Changing practice in gastrointestinal endoscopy: reducing distractions for patient safety. Gastroenterol Nursing 2016; 39: 181-185

[7] West P, Sculli G, Fore A et al. Improving patient safety and optimizing nursing teamwork using crew resource management techniques. J Nursing Admin 2012; 42: 15-20

[8] Atkins L, Hunkeler EM, Jensen CD et al. Factors influencing variation in physician adenoma detection rates: a theory-based approach for performance improvement. Gastrointest Endosc 2016; 83: 617-626. e612

[9] Rex DK, Bond JH, Winawer S et al. Quality in the technical performance of colonoscopy and the continuous quality improvement process for colonoscopy: recommendations of the U.S. Multi-Society Task Force on Colorectal Cancer. Am J Gastroenterol 2002; 97: 12961308 
[10] Wheelock A, Suliman A, Wharton R et al. The impact of operating room distractions on stress, workload, and teamwork. Ann Surg 2015; 261: 1079-1084

[11] Laborde C], Bell CS, Slaughter JC et al. Evaluation of a novel tablet application for improvement in colonoscopy training and mentoring (with video). Gastrointest Endosc 2017; 85: 559-565.e551

[12] Harris PA, Taylor R, Thielke R et al. Research electronic data capture (REDCap) - a metadata-driven methodology and workflow process for providing translational research informatics support. J Biomed Informat 2009; 42: 377-381
[13] Klimek L, Bergmann KC, Biedermann T et al. Visual analogue scales (VAS): Measuring instruments for the documentation of symptoms and therapy monitoring in cases of allergic rhinitis in everyday health care: Position Paper of the German Society of Allergology (AeDA) and the German Society of Allergy and Clinical Immunology (DGAKI), ENT Section, in collaboration with the working group on Clinical Immunology, Allergology and Environmental Medicine of the German Society of Otorhinolaryngology, Head and Neck Surgery (DGHNOKHC). Allergo J Int 2017; 26: 16-24 